\title{
Propuesta de Programa de Intervención Terapéutica en la Escuela Regular $x$
}

T.O. Concetta Giorgini

T.O. ZURELIS SANTANA

En el Centro de atención Integral del Niño Guardia Nacional de Venezuela (CENAINGUARNAC), fundado en 1992. Se desarrolló, en el Servicio de Terapia Ocupacional, una línea de investigación a partir de la experiencia profesional en el área de educación, específicamente dificultades de aprendizaje, con el objeto de identificar las alteraciones neuro-musculares que subyacen al problema (Trastorno de aprendizaje). Se evaluó el fenómeno intramuros y extramuros; escuelas regulares 1er y 2 da etapa de educación básica. Se diseño un programa de intervención preventivo y asistencial, que toma en cuenta, tanto al individuo como a su contexto. A partir de los resultados, surge el MODELO TERAPÉUTICO DE INTEGRACIÓN FUNCIONAL, compatible y perfectamente adaptable al Modelo Educativo Venezolano, planteando la conveniencia de la participación del Terapeuta Ocupacional en las escuelas regulares.

Actualmente se abren vías de comunicación con entes gubernamentales, con el objeto, de darle apoyo al programa, que atendería de forma preventiva al $25-30 \%$ (resultados de estudios de investigación) de la población en riesgo e intervendría a la población que ya presenta la disfunción escolar.

\section{EI MODELO TERAPÉUTICO DE INTEGRACIÓN FUNCIONAL (MOTIF)}

- Proporciona un sistema conceptual unificado, consistente y flexible para la práctica de la Terapia Ocupacional sobre individuos con dificultades para aprender, que permite el uso de diferentes teorías, marcos de referencias y modelos, dentro de su estructura.

- Las premisas y principios básicos del modelo son todas aquellas orientadas desde una perspectiva holística, humanística, neurofisiológica, funcionamiento ocupacional, ocupación humana, adaptación a través de la ocupación, recapitulación de la ontogénesis, desarrollo y sistémica; con técnicas del neurodesarrollo, integración sensorial, biomecánica.

- Se dirige al estudio de las limitaciones funcionales del individuo según sus capacidades neuroperceptivomotoras, cognitivas, adaptativas y relaciónales.

- Se centra, en la práctica de los individuos con dificultades de aprendizaje, aunque se ha aplicado sobre otros diagnósticos que afecten el rendimiento del niño en la escuela.

- El abordaje es centrado en el individuo.

- Se basa en la idea de que el niño requiere una serie de capacidades 
mínimas para su desempeño ocupacional (escolar), y para alcanzar y/o desarrollar el rol de estudiante ajustado a los requerimientos escolares, teniendo en cuenta la edad, cultura y entorno.

- Proporciona una metodología sistemática de planificación e intervención, que guía las acciones del terapeuta ocupacional, justifica por qué se ha tomado este camino para solucionar el problema y cómo se rige por el principio de interdisciplinaridad planteado por el Modelo de Atención Educativa Integral Especializada al Educando con Dificultades de Aprendizaje, propuesto pos el Ministerio de Educación. 1997.
- Asume la concepción del hombre como un ser bio-psico-social, interactuando de forma permanente con su entorno socio-cultural de manera dinámica en función de transformarse a sí mismo y al medio que lo rodea.

- Su intención es promover la práctica de la terapia ocupacional en el ámbito de la escuela regular, articulada desde la reflexión, desde la aplicación de las teorías en el ejercicio profesional cotidiano y desde la contribución que la experiencia en esta área aporta al corpus epistemológico.

- Su orientación, es de tipo preventiva y de intervención terapéutica, según requieran los educandos.

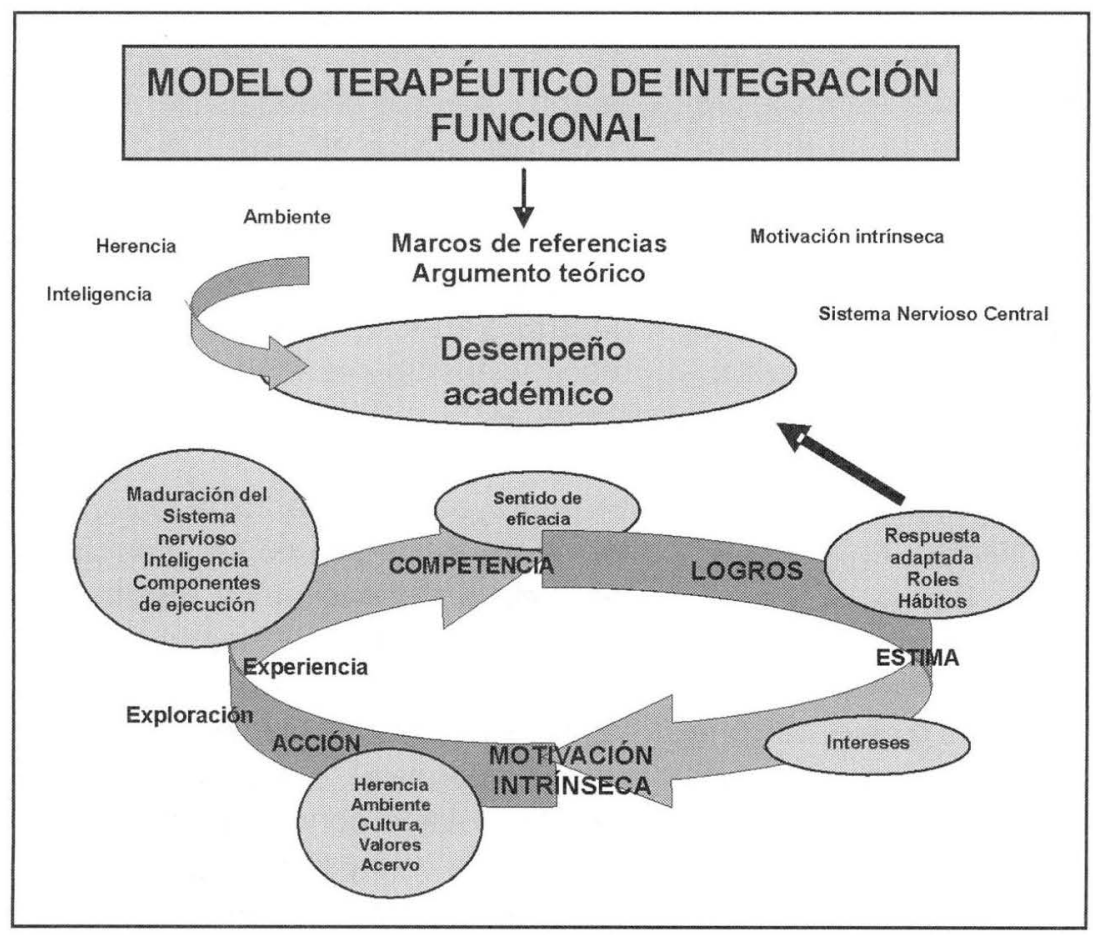

Giorgini y Santana (2004). 